\section{Gas explosion caused by argon plasma coagulation of colonic angiodysplasias}
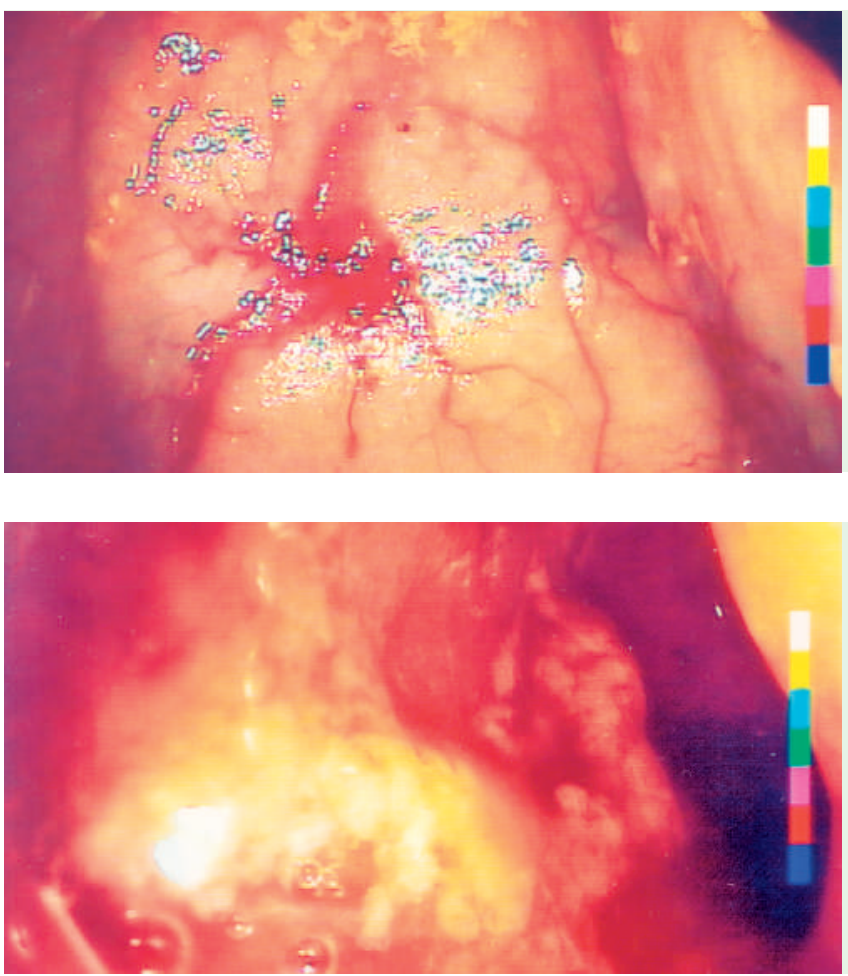

Argon plasma coagulation (APC) is a wellestablished tool to treat lesions of the gastrointestinal mucosa, such as angiodysplasias [1].

Cases of colon perforation after gas explosion caused by APC have been recorded since 1976 [2], especially after preparation with mannitol [3], which seemed to increase hydrogen gas production. Newer data suggest that stools remaining in an incompletely cleaned bowel may be the main cause for explosive gas production, rather than the type of chemical cleaning agent [4].

A 69-year-old patient initially presented to the emergency room with dyspnea and tachycardia, caused by substantial iron deficiency anemia.

Upper gastrointestinal endoscopy did not show any cause of acute or chronic bleeding, so the patient was prepared with macrogol solution (Klean Prep ${ }^{\circledR}$ ), and a colonoscopy was carried out. Angiodysplasias were discovered in the ascending colon ( $\bullet$ Figure 1 ). Immediately on starting to treat the first of these angiodysplasias with APC a loud gas explosion took place. No perforation was detectable at
Figure 1 Angiodysplasia of the right-sided colon before treatment.

Figure 2 Angiodysplasia after treatment with argon plasma coagulation.

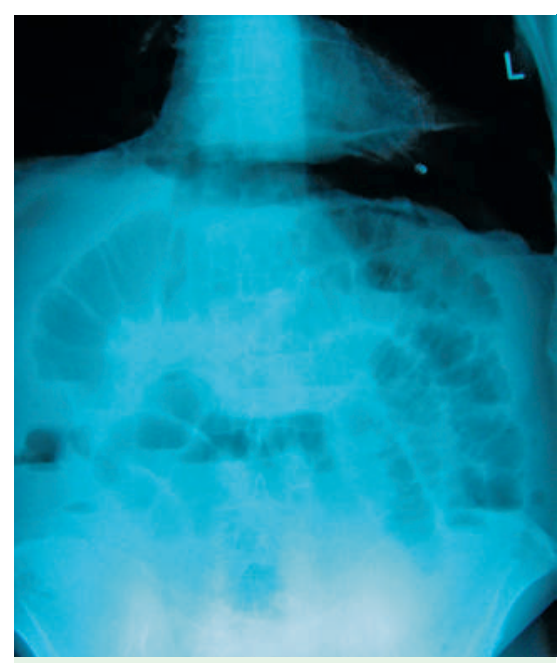

Figure 3 Free air on abdominal radiograph 2 days after intervention.

\section{Nürnberg ${ }^{1}$, H. Pannwitz ${ }^{2}$,}

\section{K. D. Burkhardt ${ }^{2}$, M. Peters ${ }^{1}$}

1 Medizinische Klinik B, Ruppiner Kliniken, Neuruppin, Germany

2 Abteilung für Innere Medizin, Oberhavel Kliniken, Oranienburg, Germany

\section{References}

1 Grund KE, Storek D, Farin G. Endoscopic argon plasma coagulation (APC) first clinical experiences in flexible endoscopy. Endosc Surg Allied Technol 1994; 2: 42-46

2 Bond JH, Levy M, Levitt MD. Explosion of hydrogen gas in the colon during proctosigmoidoscopy. Gastrointest Endosc 1976; 23: $41-42$

3 Raillat A, de Saint-Julien J, Abgrall J. Colonic explosion during an endoscopic electrocoagulation after preparation with mannitol. Gastroenterol Clin Biol 1982; 6: 301 - 302

4 Ben-Soussan E, Antonietti M, Savoye G et al. Argon plasma coagulation in the treatment of hemorrhagic radiation proctitis is efficient but requires a perfect colonic cleansing to be safe. Eur J Gastroenterol Hepatol 2004; 16: 1315-1318

\section{performed.}

The histological examination confirmed the sites of perforation, which did not match the site of the treated angiodysplasia. The patient's condition improved.

We present the first case to our knowledge of a severe colonic perforation caused by a gas explosion during APC treatment in a patient prepared with macrogol solution. This should raise awareness of the risk of explosion during APC, irrespective of the solution used for colon preparation.

Endoscopy_UCTN_Code_CPL_1AJ_2AZ
Bibliography

DOI $10.1055 / s-2007-966403$

Endoscopy 2007; 39: E182

(c) Georg Thieme Verlag KG Stuttgart · New York . ISSN 0013-726X

\section{Corresponding author}

\section{Peters, MD}

Medizinische Klinik B

Ruppiner Kliniken GmbH

Fehrbelliner Str. 38

16816 Neuruppin

Germany

Fax: +49-3391-393202

m.peters@ruppiner-kliniken.de 